\title{
KEPENTINGAN DAN PERAN AKTOR DALAM PENGELOLAAN HUTAN MANGROVE DI DESA PULAU PAHAWANG KECAMATAN MARGA PUNDUH KABUPATEN PESAWARAN
}

\section{(Actors Interest and Roles on Mangrove Forest Management in the Pulau Pahawang Village Marga Punduh Subdistrict Pesawaran Regency)}

\author{
$\mathrm{Oleh} / \mathrm{By}$
}

\author{
Iga Yulia Mustika, Asihing Kustanti, dan Rudi Hilmanto \\ Jurusan Kehutanan Fakultas Pertanian Universitas Lampung \\ Jl. Soemantri Brojonegoro No. 01 Bandar Lampung 35143 \\ E-mail : igayuliamustika@yahoo.com
}

\begin{abstract}
ABSTRAK
Hutan mangrove memiliki fungsi fisik, fungsi biologis/ekologis dan fungsi sosialekonomis. Hutan mangrove memiliki banyak manfaat yang menyebabkan berbagai kepentingan dari para aktor terhadap hutan mangrove yang ada di Desa Pulau Pahawang, Kecamatan Marga Punduh, Kabupaten Pesawaran. Penelitian ini bertujuan untuk mengidentifikasi dan mengetahui matrik kepentingan aktor dan mengetahui hasil pemetaan aktor dalam pengelolaan hutan mangrove. Penelitian ini dilaksanakan pada Agustus hingga Oktober 2015 dengan menggunakan informan kunci yaitu aparatur desa, masyarakat sekitar mangrove, dinas terkait dan Lembaga Swadaya Masyarakat (LSM).

Hasil penelitian menunjukkan terdapat enam jenis kepentingan, yaitu keberadaan jalur hijau untuk dipertahankan, jenis keragaman (biodiversity), sarana pendidikan, kebutuhan pemenuhan kayu bakar, hasil hutan non kayu dan sebagai sarana wisata. Desa Pulau Pahawang memiliki tiga kuadran, pada kuadran Subject terdapat Badan Lingkungan Hidup. Untuk kuadran keyplayers terdapat Dinas Perkebunan dan Kehutanan, Badan Pengelola Daerah Perlindungan Mangrove (BPDPM) dan LSM Mitra Bentala. Pada kuadran crowd terdapat Badan Perencanaan Pembangunan Daerah (Bappeda), Badan Pertanahan (BPN), Dinas Kelautan dan Perikanan (DKP), Dewan Perwakilan Rakyat Daerah (DPRD) dan masyarakat.
\end{abstract}

Kata kunci : hutan mangrove, kepentingan aktor, peran aktor, Pulau Pahawaang

\section{ABSTRACT}

Mangrove forest has physical, biological/ecological and social-economics functions. Mangrove forest at Pulau Pahawang Village, Marga Punduh, Subdistrict Pesawaran has many functions which causes many interest of actors. This research was aimed to identify and maping the role of actors interest. This research was conducted on August until October 2015, by using key informant namely agencies village, local communities, public figure, related department and Non-Governmental Organizations (NGO).

The result showed that there was six important aspect namely the existence of the green belt, kind of variety (biodiversity), education facilities, fire wood, non-timber forest product, and tourist facilities. Pulau Pahawang Village has three quadrant matrix interest, quadrant subject has State Ministry of The Environment. Quadrant keyplayers has 
Department of Forestry and Estate Crops, Mangrove Protected Area Management Agency (BPDPM), and Mitra Bentala as NGOs. Quadrant crowd has Development Planning Agency in Sub-National Level, Land Agency, Department of Maritime and Fisheries Affairs, Regional House of Representatives, and local.

Keyword : actor interest, mangrove forest, Pulau Pahawang, role of actor

\section{PENDAHULUAN}

Hutan mangrove umumnya terdapat di wilayah yang dipengaruhi pasang surut air laut di sepanjang pesisir (Tarigan, 2008). Hutan mangrove terdiri dari beragam organisme yang saling berinteraksi. Fungsi fisik hutan mangrove di antaranya sebagai pengendali naiknya batas antara permukaan air tanah dengan permukaan air laut ke arah daratan (intrusi), sebagai kawasan penyangga, menginduksi perluasan lahan dan melindungi garis pantai dari abrasi (Purwanto et al, 2014). Hutan mangrove memiliki banyak fungsi yang menyebabkan berbagai kepentingan terhadap hutan mangrove hadir dari para aktor, salah satunya yaitu hutan mangrove yang ada di Desa Pulau Pahawang, Kecamatan Marga Punduh, Kabupaten Pesawaran, Provinsi Lampung. Jenis kepentingan hutan mangrove cukup banyak jika dilihat dari kepentingan aktor terhadap hutan mangrove di Desa Pulau Pahawang, misalnya: keberadaan jalur hijau (green belt existing) yang tidak diubah untuk kepentingan lainnya, keanekaragaman hayati (biodiversity), dan manfaat hutan mangrove kayu dan non kayu (Kustanti et al., 2014).

\section{METODE PENELITIAN}

Penelitian ini dilaksanakan pada bulan Agustus hingga Oktober 2015. Lokasi penelitian di Desa Pulau Pahawang Kecamatan Marga Punduh, Kabupaten Pesawaran. Penetapan informan kunci yaitu dengan melihat dari segi para aktor yang memiliki kepentingan terhadap hutan mangrove, peran para aktor yang memiliki kepentingan dan pengaruh, serta masyarakat juga menjadi objek penelitian, yang melalui purposive sampling (dengan kesengajaan), dan penentuan responden dilakukan dengan snowball sampling. Snowball sampling merupakan langkah dalam penelitian kualitatif yang menyatakan bahwa apabila pengambilan data di lapangan terasa homogen maka pengambilan data dihentikan (Arikunto, 2011). Wawancara dilakukan dengan aktor-aktor yang terkait dengan penelitian ini.

Penetapan responden kunci dilakukan secara purposive sampling kemudian dilanjutkan dengan snowball sampling pada 2 orang aparatur desa Pulau Pahawang yaitu sekertaris desa dan kaur umum, masyarakat desa terdapat 2 orang ibu PKK, 2 orang petani dan 3 orang nelayan, 3 orang Pengusaha Keramba Jaring Apung (PKJA), 1 orang ketua Badan Pengelola Daerah Perlindungan Mangrove (BPDPM), serta 1 orang bagian divisi pemberdayaan masyarakat Lembaga Swadaya Masyarakat (LSM) Mitra Bentala. Aktor Dinas yang terkait adalah 1 orang bidang kehutanan di Dinas Perkebunan dan Kehutanan (Disbunhut), 2 orang Dinas Kelautan dan Perikanan (DKP), 2 orang kepala seksi Badan Pertanahan (BPN), 2 orang Badan Lingkungan Hidup (BLH), 1 orang Badan Perencanaan Pembangunan Daerah (Bappeda), dan 3 orang Dewan Perwakilan Rakyat Daerah (DPRD). Pengambilan data di lapangan pada responden yaitu langsung mewawancarai responden terpilih dengan menanyakan keadaan hutan mangrove dan peran aktor dalam pengelolaan hutan mangrove. 
Matrik kepentingan dan pemetaan para aktor dalam pengelolaan hutan mangrove akan diperoleh setelah wawancara langsung kepada aktor yang memiliki peran (kepentingan dan pengaruh) terhadap hutan mangrove. Ada pengguna langsung (direct user) dan pengguna tidak langsung (indirect user) yang memiliki berbagai kepentingan terhadap hutan mangrove, yang dapat dilihat pada Gambar 1.

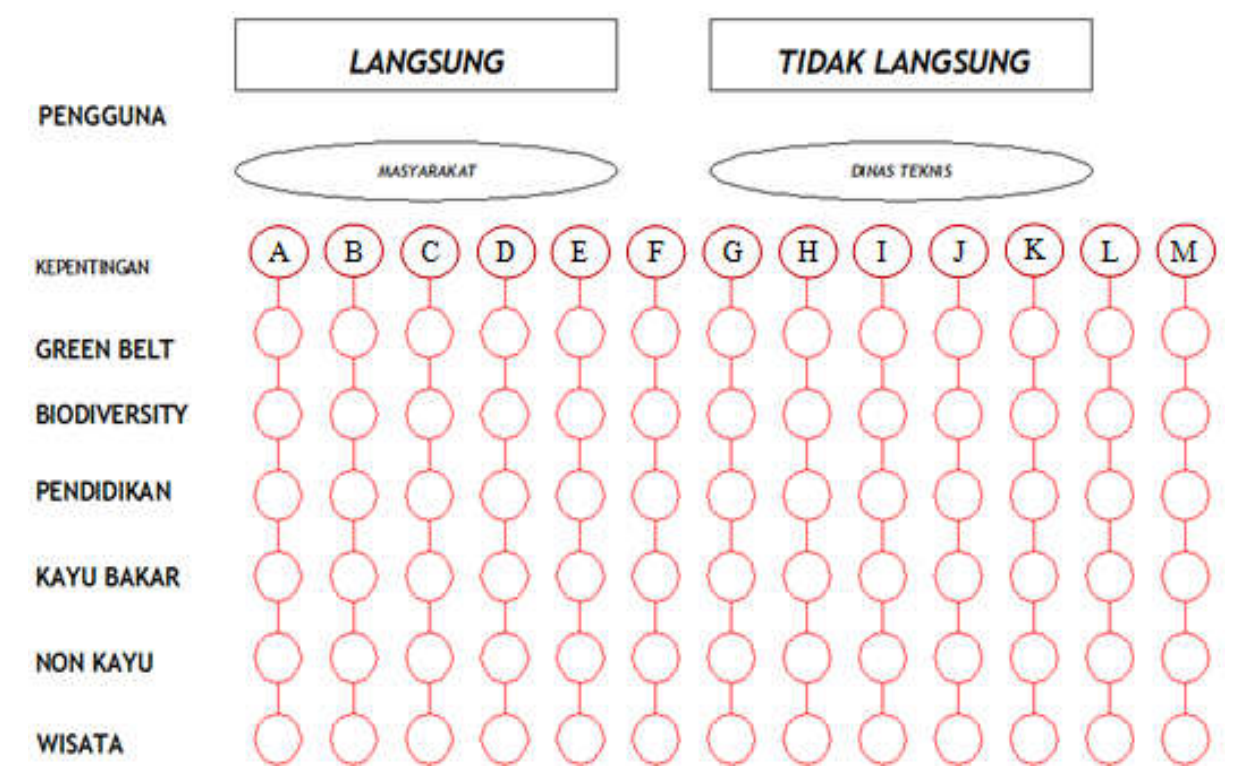

Gambar 1. Matrik kepentingan para aktor terhadap hutan mangrove dalam pengelolaan hutan mangrove di Desa Pulau Pahawang.

Keterangan

1. A merupakan aparatur desa.

2. B merupakan Badan Pengelola Daerah Perlindungan Mangrove (BPDPM).

3. C merupakan Pengusaha Keramba Jaring Apung (PKJA).

4. D merupakan masyarakat pengguna yaitu ibu PKK.

5. E merupakan masyarakat pengguna yaitu nelayan.

6. F merupakan masyarakat pengguna yaitu petani.

7. G merupakan Badan Lingkungan Hidup (BLH).

8. H merupakan Dinas Perkebunan dan Kehutanan (Disbunhut).

9. I merupakan Dinas Kelautan dan Perikanan (DKP).

10. J merupakan Badan Pertanahan (BPN).

11. K merupakan Dewan Perwakilan Rakyat Daerah (DPRD).

12. L merupakan Badan Perencanaan Pembangunan Daerah (Bappeda).

13. M merupakan Lembaga Swadaya Masyarakat (LSM) Mitra Bentala.

Pada matrik kepentingan ini akan diisi skor dari setiap aktor terhadap kepentingan hutan mangrove dengan skor dan simbol masing-masing kepentingan yaitu sangat penting $(+++)$, penting $(++)$, sedang $(+)$ dan rendah $(-)$. Penentuan skor untuk matrik ini, diperoleh dari jawaban responden yang disesuaikan dengan Skala Likert dan diselaraskan dengan Teori Krott, penggunaan metode ini bertujuan untuk melihat bagaimana potensial konflik yang akan terjadi dalam pengelolaan hutan mangrove.

Pemetaan peran para aktor diperoleh berdasarkan kepentingan (interest) dan pengaruh (power) aktor terhadap pengelolaan hutan mangrove dengan menggunakan software statistik. Peran para aktor yang dipengaruhi oleh kepentingan dan pengaruhnya dapat dilihat pada 
Gambar 2. Untuk mengetahui peran para aktor (stakeholder), maka dilakukan analisis stakeholder pada penelitian ini dengan tahapan sebagai berikut.

1. Mengidentifikasi stakeholder.

2. Mengidentifikasi peran masing-masing stakeholder sebagai subject, keyplayers, crowd dan context setter.

3. Mengetahui hubungan antara stakeholder dengan melakukan pemetaan keterkaitan stakeholder (Reed et al. 2009).

Penjelasan hubungan antara stakeholder ini antara lain.

a. Keyplayers: kepentingan tinggi dan pengaruh tinggi.

b. Context setter: kepentingan kecil, pengaruh tinggi, dan dapat menimbulkan resiko signifikan, sehingga harus dimonitor dan dikelola.

c. Subject: kepentingan tinggi, pengaruh kecil, supportif. Tidak punya kapasitas untuk mempengaruhi, tapi mampu untuk menggalang pengaruh.

d. Crowd: kepentingan kecil, pengaruh kecil, tidak perlu dipertimbangkan terlalu detil atau diikat/dilibatkan (masyarakat hanya objek).

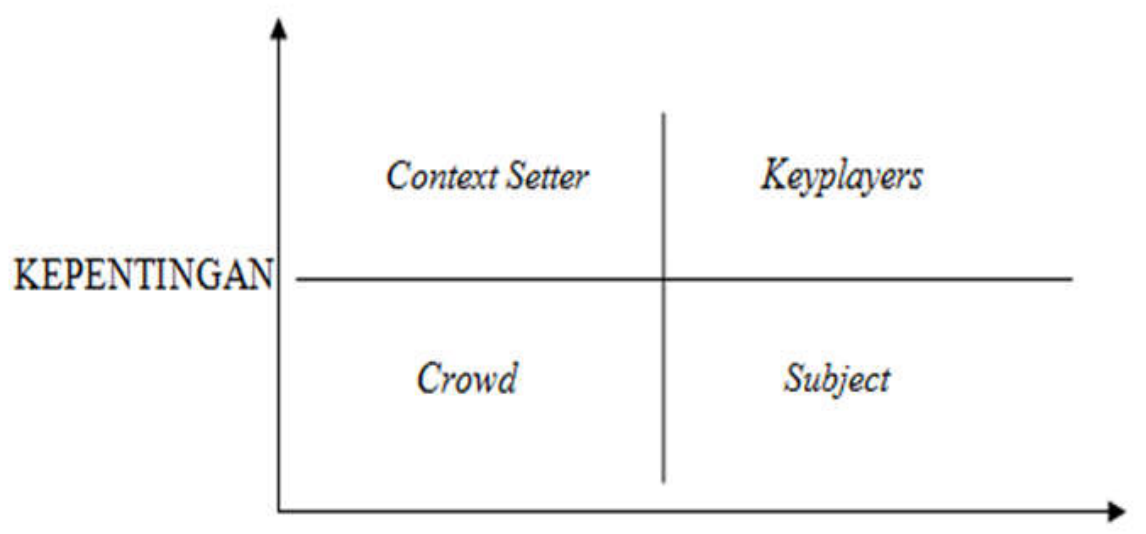

PENGARUH

Gambar 2. Pemetaan peran para aktor berbasis peran kunci (keyplayers) (Reed et al. 2009).

Pengumpulan data ini menggunakan definisi operasional untuk lebih memudahkan dalam pengukuran konsep. Definisi operasional adalah penentuan suatu nilai sehingga menjadi variabel atau variabel-variabel yang dapat diukur (Notoatmodjo, 2001).

\section{HASIL DAN PEMBAHASAN}

\section{A. Matrik Kepentingan Hutan Mangrove di Desa Pulau Pahawang}

Kepentingan dari para aktor terhadap hutan mangrove ini dimulai dengan keberadaan jalur hijau (green belt) yang tetap dipertahankan oleh setiap aktor, diiringi dengan biodiversity, kemudian kepentingan hutan mangrove sebagai sarana pendidikan bagi siswasiswi setempat yang ingin mengenal hutan mangrove dan mahasiswa yang ingin melakukan penelitian. Kepentingan hutan mangrove lainnya juga terdapat dari kayu bakar yang dapat dimanfaatkan oleh masyarakat begitu juga dengan potensi hutan mangrove dari segi non kayunya, serta kepentingan hutan mangrove sebagai sarana wisata juga sudah mulai meningkat.

Data yang didapatkan untuk memperoleh matrik kepentingan dari para aktor meliputi hasil skoring pada saat wawancara kepada responden yang menjadi aktor, skor menggunakan skala likert yang sudah ditentukan yaitu sangat kuat $(+++)$, kuat $(++)$, sedang $(+)$ dan rendah 
(-). Penentuan skor ini diperoleh dari jawaban responden yang telah diperoleh pada saat wawancara dan mengisi kuisioner yang kemudian disesuaikan dengan Skala Likert dan diselaraskan dengan (Teori Krott, 2005) yang disajikan pada Gambar 3.

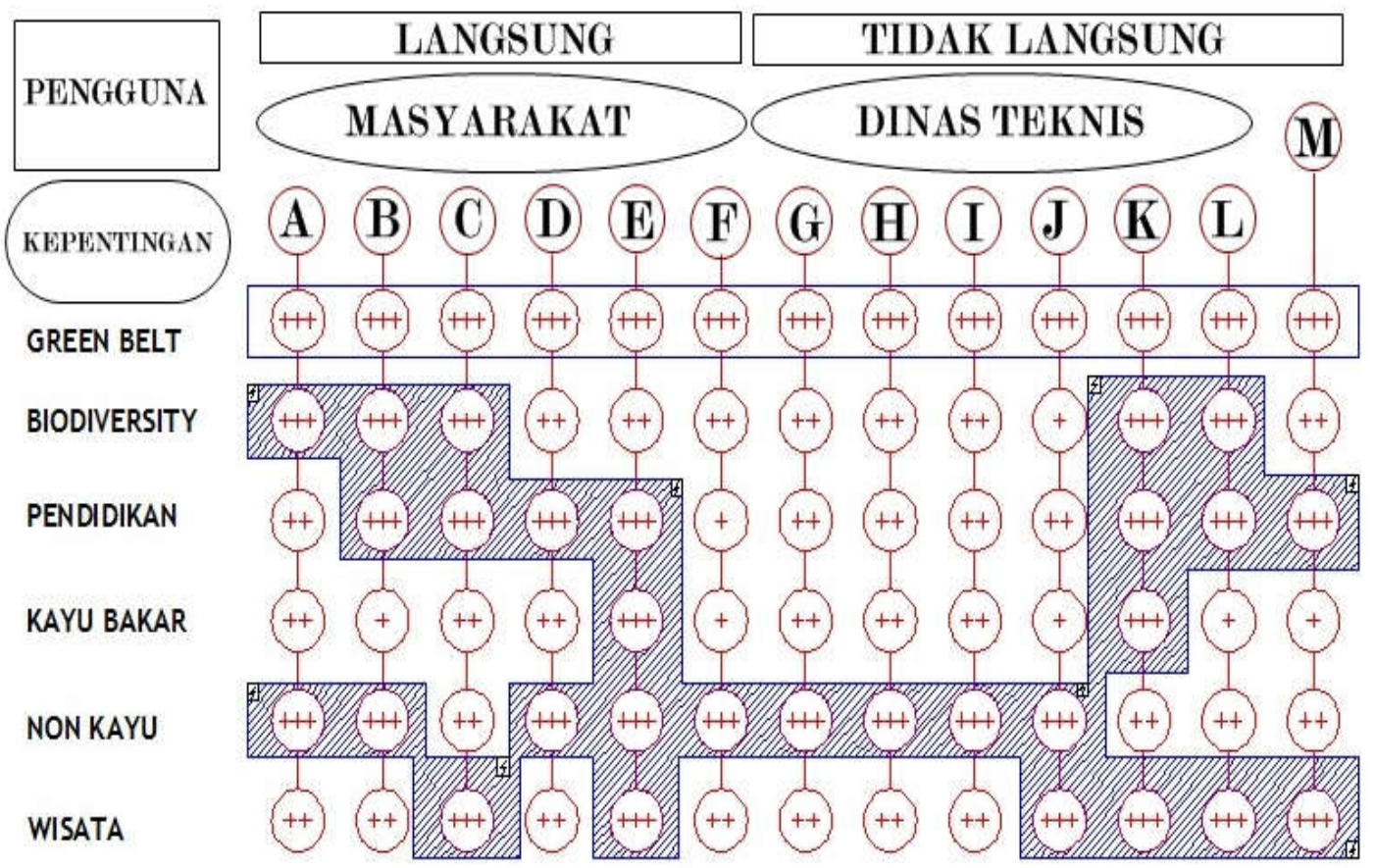

Gambar 3. Matrik Kepentingan para aktor dalam pengelolaan hutan mangrove di Desa Pulau Pahawang.

Keterangan.

1. Merupakan area utama kepentingan.

2. 2 merupakan area konflik.

3. Tanda plus tiga $(+++)$ merupakan kepentingan yang sangat kuat

4. Tanda plus dua $(++)$ merupakan kepentingan yang kuat.

5. Tanda plus satu $(+)$ merupakan kepentingan yang rendah.

6. Tidak ada tanda plus ( ) merupakan kepentingan yang rendah.

7. A merupakan aparatur desa.

8. B merupakan Badan Pengelola Daerah Perlindungan Mangrove (BPDPM).

9. C merupakan Pengusaha Keramba Jaring Apung (PKJA)

10. D merupakan masyarakat pengguna yaitu ibu PKK.

11. E merupakan masyarakat pengguna yaitu nelayan.

12. F merupakan masyarakat pengguna yaitu petani.

13. G merupakan Badan Lingkungan Hidup (BLH).

14. H merupakan Dinas Perkebunan dan Kehutanan (Disbunhut).

15. I merupakan Dinas Kelautan dan Perikanan (DKP).

16. J merupakan Badan Pertanahan (BPN).

17. K merupakan Dewan Perwakilan Rakyat Daerah (DPRD).

18. L merupakan Badan Perencanaan Pembangunan Daerah (Bappeda).

19. M merupakan Lembaga Swadaya Masyarakat (LSM) Mitra Bentala. 
Matrik kepentingan atau hasil pada Gambar 3 diringkas dan diperjelas kedalam bentuk tabel, untuk memfokuskan hasil yang diperoleh mengenai area utama kepentingan dan area potensial konflik yang terjadi dan siapa saja aktor yang terkait pada setiap kepentingan, serta apa saja penyebab konflik yang akan terjadi, yang disajikan pada Tabel 1 berikut ini.

Tabel 1. Ringkasan kepentingan hutan mangrove, aktor, dan potensial konflik dalam pengelolaan hutan mangrove di Desa Pulau Pahawang.

\begin{tabular}{|c|c|c|}
\hline Kepentingan & Aktor & Potensial Konflik \\
\hline $\begin{array}{l}\text { Keberadaan jalur hijau (green belt) } \\
\text { Untuk dilindungi tidak digunakan } \\
\text { ke fungsi lain. }\end{array}$ & $\begin{array}{l}\text { - Masyarakat } \\
\text { - Bappeda } \\
\text { - DPRD } \\
\text { - DKP } \\
\text { - Disbunhut } \\
\text { - BLH } \\
\text { - LSM Mitra Bentala } \\
\text { - Nelayan }\end{array}$ & $\begin{array}{l}\text { Tidak terjadi konflik, karena semua aktor } \\
\text { menginginkan jalur hijau (green belt) tetap } \\
\text { dipertahankan dan tidak digunakan ke } \\
\text { fungsi lain. }\end{array}$ \\
\hline $\begin{array}{l}\text { Jenis Keragaman (biodiversity) } \\
\text { Dilihat dari aspek komposisi, } \\
\text { keragaman, kepadatan jenis } \\
\text { mangrove. }\end{array}$ & $\begin{array}{l}\text {-Aparatur desa } \\
\text {-BPDPM } \\
\text {-PKJA } \\
\text {-DPRD } \\
\text {-Bappeda } \\
\text {-BPN } \\
\text {-Nelayan }\end{array}$ & $\begin{array}{l}\text { Perbedaan tujuan kepentingan aktor } \\
\text { (BPDPM dan PKJA), serta keinginan } \\
\text { terhadap kegunaan biodiversity yang ada. } \\
\text { Perbedaan semua aktor dan BPN. }\end{array}$ \\
\hline $\begin{array}{l}\text { Pendidikan } \\
\text { Keberadaan hutan mangrove untuk } \\
\text { menjadi media pendidikan dan } \\
\text { penelitian. }\end{array}$ & $\begin{array}{l}\text { - BPDPM } \\
\text { - PKJA } \\
\text { - PKK } \\
\text { - DPRD } \\
\text { - Bappeda } \\
\text { - LSM Mitra Bentala } \\
\text { - Petani }\end{array}$ & $\begin{array}{l}\text { Tidak terjadi konflik karena beberapa } \\
\text { aktor yang memiliki kepentingan sangat } \\
\text { tinggi sama-sama memiliki tujuan } \\
\text { kepentingan yang sama. }\end{array}$ \\
\hline $\begin{array}{l}\text { Kayu bakar } \\
\text { Pemenuhan kebutuhan rumah } \\
\text { tangga. }\end{array}$ & $\begin{array}{l}\text { - Nelayan } \\
\text { - DPRD } \\
\text { - Petani } \\
\text { - BPN }\end{array}$ & $\begin{array}{l}\text { Tidak terjadi konflik karena setiap aktor } \\
\text { sudah memahami aturan dalam } \\
\text { pengambilan kayu bakar dan sudah } \\
\text { memahami dampak yang akan terjadi. } \\
\text { Tetapi terdapat perbedaan tujuan aktor. }\end{array}$ \\
\hline $\begin{array}{l}\text { Produk Non Kayu } \\
\text { Variasi produk hutan non kayu di } \\
\text { sekitar hutan mangrove. }\end{array}$ & $\begin{array}{l}\text { - Aparatur desa } \\
\text { - BPDPM } \\
\text { - PKK } \\
\text { - DPRD } \\
\text { - Nelayan } \\
\text { - Petani } \\
\text { - BLH } \\
\text { - Disbunhut } \\
\text { - DKP } \\
\text { - BPN }\end{array}$ & $\begin{array}{l}\text { Manfaat yang dirasakan aktor dan } \\
\text { bagaimana keberlanjutan produk hasil } \\
\text { hutan mangrove, seperti keripik, sirup } \\
\text { ataupun hasil non kayu lainnya. }\end{array}$ \\
\hline $\begin{array}{l}\text { Wisata } \\
\text { Pemanfaatan hutan mangrove untuk } \\
\text { dijadikan objek wisata. }\end{array}$ & $\begin{array}{l}\text { - PKJA } \\
\text { - Nelayan } \\
\text { - BPN } \\
\text { - DPRD } \\
\text { - Bappeda } \\
\text { - LSM Mitra Bentala }\end{array}$ & $\begin{array}{l}\text { Manfaat yang diperoleh serta dampak } \\
\text { yang akan terjadi. }\end{array}$ \\
\hline
\end{tabular}


Hasil yang dijadikan matrik kepentingan para aktor ini diperoleh berdasarkan pendekatan dari teori Krott (2005) dan disesuaikan dengan keadaan lokasi penelitian yang dapat dibedakan menjadi 6 kepentingan, antara lain: keberadaan jalur hijau (green belt), biodiversity, pendidikan, kayu bakar, non kayu dan wisata. Secara keseluruhan kepentingan para aktor terhadap keberadaan hutan mangrove dapat dilihat pada Gambar 3. Matrik kepentingan ini menunjukan bagaimana kepentingan masing-masing aktor terhadap keberadaan hutan mangrove, area utama kepentingan serta ada area konflik yang dapat terjadi di antara aktor yang satu dengan yang lainnya. Matrik kepentingan ini kemudian dibuat dalam bentuk ringkasan seperti pada Tabel 1 yang berguna untuk mempermudah dalam membaca hasil dari matrik kepentingan.

\section{a. Kepentingan terhadap Keberadaan Jalur Hijau (Green Belt)}

Jalur hijau (green belt) adalah hutan yang didalamnya didominasi oleh vegetasi bakau yang tumbuh pada kawasan pesisir pantai yang lebarnya proporsional dengan bentuk dan kondisi fisik penting yang dibangun sejajar dengan pantai (Sriyana, 2005). Sabuk hijau ini merupakan kepentingan hutan mangrove yang pertama yang dilihat dari aspek ekologi, ekonomi dan sosial. Ketiga aspek ini merupakan aspek penting yang terdapat didalam sabuk hijau. Aspek ekologi misalnya dengan sistem perakaran yang kokoh, ekosistem hutan mangrove mempunyai kemampuan meredam gelombang, menahan lumpur dan melindungi pantai dari abrasi, dan gelombang pasang (Rahmawaty, 2006). Selain itu fungsi sosial dan ekonomi sebagai peningkatan kondisi ekonomi dan sosial masyarakat sekitar hutan yang memanfaatkan hasil hutan mangrove baik hasil hutan kayu dan non kayunya (Kustanti, 2011).

Untuk kepentingan yang pertama ini tidak terjadi konflik ataupun menimbulkan potensial konflik karena semua aktor menginginkan jalur hijau tetap dipertahankan dan tidak diperuntukan untuk penggunaan lainnya. Kepentingan jalur hijau (green belt) ini juga terdapat di Lampung Mangrove Center (LMC) yang seluruh aktornya menginginkan jalur hijau tetap dipertahankan (Kustanti, 2013). Pada kepentingan ini semua aktor memiliki pendapat yang sama dan tingkat kepentingan yang sama yaitu skor 7 dengan simbol (+++) untuk keberadaan jalur hijau, karena jalur hijau merupakan faktor utama yang dapat mempertahankan dan melindungi keberadaan Desa Pulau Pahawang dari erosi, anrasi dan mencegah intrusi air laut.

\section{b. Kepentingan terhadap Keberadaan Biodiversity}

Kepentingan yang kedua yaitu jenis keragaman (biodiversity) yang dilihat dari komposisi, keragaman dan kepadatan. Pada kepentingan ini yang menganggap sangat penting dengan skor 7 dan simbol (+++) antara lain Aparatur Desa, BPDPM, PKJA, DPRD dan Bappeda. Pada kepentingan ini yang berpotensial konflik adalah antara BPDPM, PKJA, dan BPN. Pada kepentingan ini BPN menganggap rendah dengan skor 3 dan simbol $(+)$. Kedua aktor yaitu BPDPM dan PKJA sama-sama menganggap biodiversity ini sangat penting tetapi dengan jenis kepentingan dan tujuan yang sangat berbeda.

Kedua aktor ini yang paling terlihat perbedaannya yaitu PKJA menganggap ini sangat penting dengan tujuannya untuk kesehatan dan keberlangsungan usaha kerambah jaring apung yang merupakan usaha dan sumber penghasilannya sendiri, maka berbeda dengan kepentingan aktor BPDPM yang menganggap biodiversity ini sangat penting dikarenakan banyak jenis atau keragaman dalam hutan mangrove di Desa Pulau Pahawang ini yang tidak dimiliki oleh hutan mangrove di daerah lainnya. BPDPM berpendapat jika ini tetap dipertahankan dengan maksud untuk menjaga kelestariannya maka akan dirasakan oleh banyak orang dan masyarakat setempat serta menjadi panutan bagi pengelola hutan mangrove di daerah lainnya. Namun tetap saja potensial konflik ini tidak berdampak besar dalam waktu dekat karena masih banyak aktor yang ingin biodiversity hutan mangrove ini tetap ada dengan 
semestinya. Kepentingan biodiversity ini merupakan salah satu kepentingan yang dikatakan kuat atau penting. Berbeda dengan kepentingan lainnya yang memiliki nilai sangat penting atau skor 7, tingkat kepentingan pada biodiversity. Kepentingan yang tinggi ini terjadi karena masyarakat yang berprofesi sebagai nelayan hanya melihat dan menilai dari 2 aspek saja, serta adanya nelayan yang masih belum memahami manfaat sebenarnya pada hutan mangrove. Kepentingan biodiversity ini juga bagi nelayan tidak dirasakan secara langsung atu dapat dikatakan tidak menghasilkan nilai ekonomi serta manfaat lain yang dirasakan secara langsung, sehingga masyarakat yang berprofesi sebagai nelayan ini menilai penting saja.

\section{c. Kepentingan terhadap Pendidikan}

Kepentingan hutan mangrove Desa Pulau Pahawang sebagai sarana pendidikan, merupakan kepentingan ketiga yang dianggap sangat penting oleh 7 dari 13 aktor yaitu BPDPM, PKJA, ibu-ibu PKK, nelayan, DPRD, Bappeda dan LSM Mitra Bentala. Sebagian besar yang menganggap salah satu kepentingan hutan mangrove sebagai sarana pendidikan ini sangat penting adalah masyarakat setempat, karena di dunia pendidikan masyarakat setempat yang tinggal di Desa Pulau Pahawang, hutan mangrove dijadikan mata pelajaran bagi siswanya agar mereka memahami dan mengerti pentingnya hutan mangrove serta dapat mempelajarinya secara langsung. Dengan adanya mata pelajaran ini masyarakat menganggap keberadaan hutan mangrove sangat penting agar ketika anak-anak mereka mendapat pengenalan tentang hutan mangrove mereka dapat melihat dan mengenal hutan mangrove sacara langsung, tidak hanya mendengarkan penjelasan atau materi dari pengajar saja.

Kepentingan hutan mangrove sebagai sarana pendidikan ini juga didukung oleh DPRD, Bappeda dan LSM Mitra Bentala. Ketiga aktor ini memiliki pendapat dan tujuan yang sama, bagi mereka tidak hanya siswa setempat saja tetapi siswa di luar Desa Pulau Pahawang dan para mahasiswa yang membutuhkan hutan mangrove sebagai salah satu media pendidikan dan penelitian ini menjadi sangat terbantu jika keberadaan hutan mangrove di desa ini selalu dijaga keberadaannya.

Aspek pendidikan pada hutan mangrove di Desa Pulau Pahawang ini juga sudah pantas untuk dikatakan layak sebagai saran pendidikan, karena telah memenuhi 4 syarat yang ada. Aspek pendidikan hutan mangrove dikatakan layak dijadikan sebagai wisata pendidikan apabila:

a. Mempunyai Lembaga, agar dapat berjalan dengan baik maka diperlukan seksi penelitian, pelatihan, informasi, ekowisata dan pendidikan lingkungan.

b. Adanya jalan sebagai sarana mengelilingi mangrove.

c. Tatanan mangrove tanpa merubah zonasi dari mangrove itu sendiri.

d. Tidak adanya pedagang liar yang berada di kawasan wisata (Wijayanti, 2009).

\section{d. Kepentingan Kayu Bakar}

Kepentingan keempat yaitu sebagai pemenuhan kebutuhan dan penggunaan kayu bakar. Pada kepentingan keempat ini hanya dua aktor yang menganggap ini sangat penting dengan skor 7 dan simbol $(+++)$ yaitu nelayan dan DPRD. Kedua aktor ini menganggap kepentingan kayu bakar sangat penting dikarenakan untuk kepentingan masyarakat setempat. Aktor DPRD menganggap kayu bakar ini sangat penting karena melihat beberapa masyarakat yang masih sangat membutuhkan kayu bakar.

Pendapat ini dibenarkan oleh masyarakat Desa Pulau Pahawang yang berprofesi sebagai nelayan, aktor ini menganggap kayu bakar sangat penting karena dapat membantu dalam pemenuhan rumah tangga yaitu untuk memperoleh kayu bakar. Selain sebagai pemenuhan kebutuhan rumah tangga, beberapa masyarakat menganggap sangat sayang apabila kayu bakar yang telah layak di ambil justru dibiarkan terbuang begitu saja, oleh karena itu pihak aparatur desa juga memberikan izin kepada masyarakat yang masih 
membutuhkan kayu bakar dengan syarat dn ketentuan yang telah diberlakukan di Desa Pulau Pahawang ini, sehingga hasil kayu bakar di Desa Pulau Pahawang tetap ada dan berkelanjutan serta perlu dirawat dengan baik. Menurut Kustanti (2013), perlu adanya penelitian tentang kayu bakar (jenis, ukuran, umur, kriteria kayu, dan lokasi) agar semua aktor semakin memahami bagaimana seharusnya bertindak terhadap keberadaan hasil kayu hutan mangrove.

\section{e. Kepentingan terhadap Produk Non Kayu}

Kepentingan kelima yaitu hutan mangrove sebagai hasil hutan non kayu. Kepentingan hasil hutan non kayu ini dianggap sangat penting oleh hampir semua aktor yaitu Aparatur Desa, BPDPM, PKK, nelayan, petani, BLH, Disbunhut, DKP dan BPN. Semua aktor yang menganggap non kayu sangat penting beranggapan bahwa pengelolaan hasil hutan non kayu sangat berguna untuk kemajuan masyarakat di Desa Pulau Pahawang dan dapat menjadi salah satu sumber pendapatan masyarakat terutama ibu-ibu PKK.

Hasil hutan non kayu di hutan mangrove Desa Pulau pahawang ini juga dapat dikatakan relatif banyak dari pohon mangrove sendiri sampai hasil biota lautnya. Hasil hutan non kayu ini antara lain:

a. Khasiat kulit batang $R$. mucronata adalah untuk mengobati beri-beri, sedangkan kulit batang, bunga, daun dan akar dapat mengobati hepatitis (Purnobasuki, 2004).

b. Buah pedada $S$. alba dapat dijadikan bahan pembuatan dodol, permen, lempok, wajik, jus dan sabun cair pedada (Priyono et. al., 2010), di Desa Pulau Pahawang ini sudah sering memproduksi dodol dan sirup pedada.

c. Serta keripik mangrove dari daun jeruju (A. ilicifolius) yang juga biasa dijadikan sebagai pewarna pakaian, dan ada hasil biota lautnya seperti rebon dan cacing.

Produk non kayu ini diberikan nilai penting saja bagi DPRD dibandingkan dengan lima kepentingan lainnya yang seluruhnya merupakan kepentingan yang sangat kuat dalam hutan mangrove. Hal ini terjadi karena DPRD menilai bahwa masyarakat sudah mampu memenuhi kebutuhan ekonominya melalui kepentingan lain, misalnya kepentingan hutan mangrove sebagai sarana wisata. Namun hal ini tidak berpengaruh konflik karena DPRD tidak menganggap bahwa kepeentingan produk non kayu ini dengan nilai kepentingan yang rendah.

Kepentingan hutan mangrove dari hasil non kayu memang dianggap sangat penting oleh sebagian aktor dan potensial konflik juga tidak terlihat antar aktor, karena hampir semua aktor beranggapan hal ini dapat memajukan dan mensejahterakan masyarakat desa, yang apabila dikelola secara serius dan baik, akan memberikan hasil lestari dan memiliki nilai ekonomi. Hanya saja dampak yang dikhawatirkan akan terjadi kedepannya adalah apakah produk non kayu yang sudah diusahakan oleh masyarakat ini akan terus berjalan dan terus mendapat dukungan dari pemerintah dan Dinas terkait atau tidak. Selain itu keberlanjutan hutan mangrove juga menjadi alasan utama bagi masyarakat yang mengelola hasil non kayu karena apabila hasil non kayu tetap diproduksi tetapi tidak memperhatikan sistem, waktu dan pola pemanfaatan atau pengambilan yang teratur maka akan merusak keberadaan hutan mangrove Desa Pulau Pahawang ini.

Kepentingan dari petani ini terdapat tiga kepentingan yang sangat jelas perbedaan tingkat kepentingannya, yaitu apabila petani menganggap produk non kayu sangat penting sangat berbeda ketika mereka menganggap kepentingan pendidikan dan kayu bakar yaitu sangat tinggi. Kepentingan yang sangat berbeda ini terjadi karena petani lebih merasakan manfaat dari pengelolaan hutan mangrove dengan kepentingan produk non kayunya, karena non kayu memiliki hasil yang dapat dirasakan oleh petani. Produk non kayu yang dianggap dapat menghasilkan nilai ekonomi ini juga dianggap dapat dilakukan dan dijalankan oleh 
masyarakat yang berprofesi petani ini, selain bahan yang tersedia dan dapat diperoleh dengan mudah, aktor ini juga dapat melaksanakan pekerjaan utamanya sebagai petani. Jika dibandingkan dengan pendidikan dan kayu bakar jelas para petani lebih memilih produk non kayu sangat penting dibandingkan dengan kepentingan lainnya.

\section{f. Kepentingan sebagai Sarana Wisata}

Kepentingan keenam adalah kepentingan hutan mangrove sebagai sarana wisata, pada kepentingan ini yang menganggap sangat penting dengan skor 7 adalah PKJA, Nelayan, BPN, DPRD, Bappeda, dan LSM Mitra Bentala. Pada kepentingan ini beberapa aktor berpotensial konflik melihat seberapa besar dampak yang terjadi. Jika dilihat di beberapa tempat wisata justru mengancam keberadaan mangrove inilah yang menyebabkan beberapa aktor lainnya menganggap wisata ini tidak seberapa penting, tetapi jika masyarakat memiliki aspek kunci untuk mengelola maka keadaan dilapangan akan lebih baik. Kepentingan sebagai sarana wisata sebaiknya memiliki aspek kunci berbasis masyarakat yaitu.

a. Masyarakat membentuk panitia atau lembaga untuk pengelolaan kegiatan ekowisata di daerahnya, dengan dukungan dari pemerintah dan organisasi masyarakat.

b. Prinsip local ownership (pengelolaan dan kepemilikan oleh masyarakat setempat) diterapkan sedapat mungkin terhadap sarana dan prasarana ekowisata, kawasan ekowisata.

c. Homestay menjadi pilihan utama untuk sarana akomodasi di lokasi wisata.

d. Pemandu adalah orang setempat (nilai partisipasi masyarakat).

e. Perintisan, pengelolaan dan pemeliharaan obyek wisata menjadi tanggung jawab masyarakat setempat (Direktorat Jenderal Pengembangan Destinasi Pariwisata, 2009).

Matrik kepentingan ini menunjukan bahwa setiap aktor baik masyarakat maupun Dinas terkait menganggap keberadaan kepentingan hutan mangrove sangat tinggi. Kepentingan-kepentingan yang tinggi inilah yang perlu diketahui apakah mendukung keberadaan mangrove atau justru merusak. Tetapi kenyataannnya seluruh aktor menganggap hutan mangrove sangat penting dan mendukung keberlanjutan hutan mangrove ini, hanya saja ada yang menjaga dan merawat secara langsung dan ada yang melalui program-program yang telah ditetapkan dan dijadwalkan secara teratur dari para aktor atau pengguna tidak langsung.

Dilihat dari matrik ini sesama aktor harus saling memberi koordinasi yang jelas antara masyarakat dan Dinas terkait agar tidak terjadi konflik yang meluas dan tidak terjadi pula kepentingan pribadi masing-masing aktor yang lebih diutamakan. Sejauh ini pengelolaan hutan mangrove di desa Pulau Pahawang masih terjaga dengan baik hubungannya antara badan pangelolaan dalam masyarakat serta pemerintah Kabupaten Pesawaran.

\section{Pemetaan Para Aktor dalam Pengelolaan Hutan Mangrove di Desa Pulau Pahawang}

Pemetaan para aktor ini menjelaskan tentang bagaimana peran (pengaruh dan kepentingan) masing-masing aktor terhadap keberlanjutan hutan mangrove di Desa Pulau Pahawang. Dimana hasil pemetaan ini diperoleh dari hasil skoring setiap aktor terhadap aktor lain yang dilakukan saat wawancara bagaimana tingkat kepentingannya serta seberapa besar pengaruh setiap aktor yang dinilai terhadap keberadaan hutan mangrove di Desa Pulau pahawang ini. Hasil skoring yang didapatkan meliputi tingkat kepentingan dan pengaruh aktor terhadap keberadaan hutan mangrove di Desa Pulau Pahawang yang disajikan pada Tabel 2. 
Tabel 2. Kepentingan aktor terhadap keberadaan hutan mangrove di Desa Pulau pahawang.

\begin{tabular}{clcc}
\hline No & \multicolumn{1}{c}{ Responden } & Kepentingan & Kepentingan \\
\hline 1. & Bappeda & 2.92 & 2.85 \\
2. & BLH & 3.69 & 4.31 \\
3. & DKP & 3.00 & 3.77 \\
4. & DISBUNHUT & 4.31 & 4.62 \\
5. & BPN & 2.15 & 1.92 \\
6. & LSM Mitra Bentala & 5.15 & 5.69 \\
7. & DPRD & 2.62 & 2.62 \\
8. & BPDPM & 4.92 & 5.85 \\
9. & Masyarakat & 3.69 & 3.69 \\
\hline
\end{tabular}

Nilai skor pengaruh dan kepentingan yang telah diperoleh ini kemudian dipetakan kedalam bentuk pemetaan para aktor menggunakan software statistic. Pada hasil pemetaan ini akan menjelaskan bagaimana posisi aktor atas perannya terhadap hutan mangrove yangi terbagi kedalam empat kuadran antara lain: subject, keyplayers, crowd, dan context setter yang dapat dilihat pada Gambar 4.

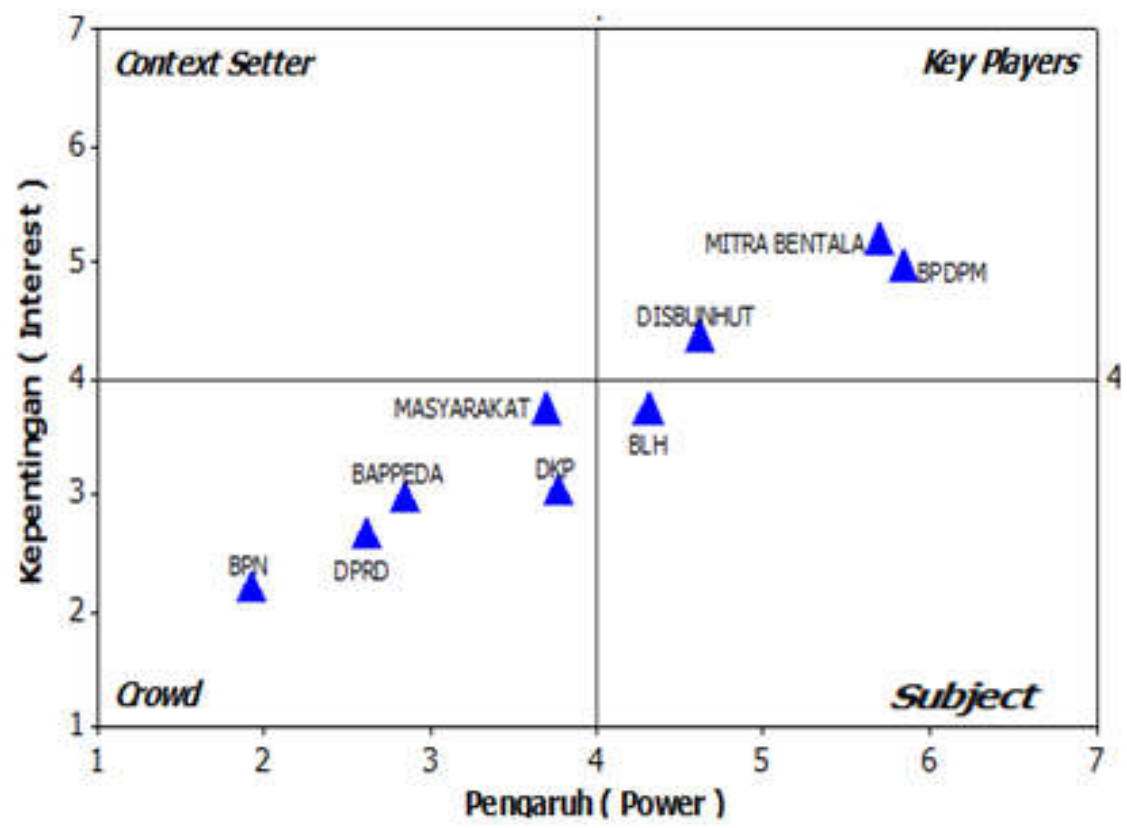

Gambar 5. Pemetaan para aktor dalam pengelolaan hutan mangrove di Desa Pulau Pahawang.

Peran para aktor dalam hal kepentingan dan pengaruhnya dalam pengelolaan hutan mangrove di Desa Pulau Pahawang ini dapat dilihat pada Gambar 5 di atas. Pada Gambar 5 ini diperoleh hasil pemetaan peran para aktor dan dapat dilihat bahwa masing masing aktor berada dikuadrannya masing-masing yaitu context setter, keyplayers, dan crowd, sedangkan pada hutan mangrove Desa Pulau Pahawang ini tidak terdapat aktor pada kuadran subject.

\section{Kuadran Keyplayers}

Keberadaan hutan mangrove di Desa Pulau Pahawang ini terlihat para aktor yang berada pada kuadran keyplayers adalah Dinas perkebunan dan Kehutanan (Disbunhut) dengan 
pengaruh 4,62 dan kepentingan 4,31, Lembaga Swadaya Masyarakat (LSM) Mitra Bentala dengan pengaruh 5,69 dan kepentingan 5,15, dan Badan Pengelola Daerah Perlindungan Mangrove (BPDPM) dengan pengaruh 5,85 dan kepentingan 4,92.

Peran Disbunhut dalam hal ini sesuai dengan kuadran dan tupoksinya sehingga wajar jika Disbunhut berada di kuadran keyplayers, selain memang bagian tugasnya, aktor ini memiliki kepentingan yang tinggi untuk mengetahui bagaimana kelanjutan dan keadaan hutan mangrove secara berkala. Begitu juga dengan pengaruhnya karena Disbunhut memiliki tugas dan fungsi terhadap hutan mangrove untuk berperan kepada masyarakat dalam melakukan program-program terkait keberadaan dan kebelangsungan hutan mangrove, seperti sosialisasi kepada masyarakat yang rutin dilakukan setiap 2 bulan sekali.

Tupoksi dari aktor yang berada pada kuadran keyplayers ini membuat tingkat pengetahuan yang dimiliki keyplayers lebih dalam dibanding pemangku kepentingan yang lain. Sama dengan tingkat kepentingan Kementerian Kehutanan sebagai keyplayers dalam perumusan kebijakan fiskal hijau yang dinyatakan oleh Nurfatriani (2015), kepentingan Disbunhut juga meliputi kepentingan yang sama yaitu ekonomi, sosial, dan lingkungan. Aktor juga memiliki kepentingan untuk terus mengelola hutan mangrove agar dapat terus bermanfaat bagi masyarakat sekitar.

\section{Kuadran Subject}

Kuadran Subject ini terdapat satu aktor yaitu Badan Lingkungan Hidup (BLH). BLH ini memiliki nilai pengaruh 4,31 dan kepentingan 3,69. Badan Lingkungan Hidup Kabupaten Pesawaran ini, memiliki kepentingan dan kewajiban, terhadap lingkungan hidup di hutan mangrove Desa Pulau Pahawang. BLH subang juga terdapat pada kuadran subject seperti BLH Pesawaran ini, yang artinya BLH dapat melakukan kontribusi berupa dukungan kebijakan dan program-program terkait, pendampingan kelompok dan bantuan teknis, serta dapat melakukan pengembangan kerjasama dengan lembaga lainnya (ICWRMIP, 2013). Dalam arti stakeholder yang berada dalam kuadran ini memiliki kepentingan sangat kuat sehingga perlu terwakilkan dalam program. Mereka bisa menjadi penting untuk mempengaruhi aktor yang lebih kuat, dan kepentingannya perlu dilindungi (Nurfatriani et al, 2015).

\section{Kuadran Crowd}

Peran aktor yang ke tiga yaitu crowd, pada arah ini terdapat lima aktor yang berada pada kuadran ini dengan kepentingan kecil dan pengaruh yang kecil juga. Aktor-aktor ini antara lain: Badan Perencanaan Pembangunan Daerah (Bappeda) dengan pengaruh 2,85 dan kepentingan 2,93, Badan Pertanahan (BPN) dengan pengaruh 1,92 dan kepentingan 2,15, Dinas Kelautan dan Perikanan (DKP) dengan pengaruh 3,77 dan kepentingan 3,00, dan Dewan Perwakilan Rakyat Daerah (DPRD) dengan pengaruh 2,62 dan kepentingan 2,62 juga, serta masyarakat Desa Pulau Pahawang dengan pengaruh 5,15 dan kepentingan 3,69.

Aktor dengan tingkat kepentingan dan pengaruh yang rendah ini diklasifikasikan sebagai pengikut lain (crowd). Diperlukan sedikit pertimbangan untuk melibatkan aktor ini lebih jauh karena kepentingan dan pengaruh yang dimiliki biasanya dapat berubah seiring berjalannya waktu, sehingga harus tetap dimonitor (Wakka, 2014). Pada posisi ini para aktor seperti BPN, DPRD, Bappeda dan DKP tidak perlu diperhitungkan terlalu detil dalam pengelolaan hutan mangrove tetapi mereka dapat memberi dampak pada pengelolaan hutan kedepannya. Keempat aktor ini hanya sebagai advokator untuk tercapainya pengelolaan hutan mangrove yang seharusnya, kepentingan khusus terhadap pengelolaan ini lebih rendah dari pemangku kepentingan lainnya. Keadaan ini dapat dikatakan karena pada kuadran ini beberapa aktor memang memiliki skor pengaruh dan kepentingan yang relatif kecil, dimana 
para aktor ini hanya sebatas melaksanakan tugas dan perintah yang telah dibuat. Sehingga pengaruh terhadap hutan mangrove cukup kecil disamping kegiatan berkala yang sudah jarang dilakukan.

\section{Kuadran Context Setter}

Hasil pemetaan peran para aktor memiliki satu kuadran yang tidak ada aktor terkait yaitu kuadran context setter. Kuadran ini merupakan kuadran yang memiliki aktor dengan kepentingan kecil dan pengaruh yang tinggi, yang apabila tidak dimonitor dan dikelola dengan baik dapat menimbulkan resiko bagi keberadaan Hutan Mangrove. Aktor dalam kuadran ini dapat memainkan perannya dalam intermediasi, penyebaran informasi dan mengadvokasi hak-hak masyarakat sekitar kawasan, seperti informasi teknik penanaman, pemilihan jenis dan penyediaan bibit serta pemasaran hasil yang dapat menunjang peningkatan kesejahteraan masyarakat (Garsetiasih dan Alikodra, 2015).

Peran para aktor ini dapat dikategorikan mendukung atau mengancam, keberadaan hutan mangrove di Desa Pulau Pahawang.

\section{KESIMPULAN DAN SARAN}

Kesimpulan dari penelitian ini adalah sebagai berikut:

1. Matrik kepentingan hutan mangrove di Desa Pulau Pahawang terdapat enam kepentingan, yaitu keberadaan jalur hijau (Green belt) untuk dipertahankan, jenis keragaman (biodiversity), sarana pendidikan, kebutuhan pemenuhan kayu bakar, hasil hutan non kayu dan sebagai sarana wisata. Aktor yang memiliki kepentingan antara lain: pengguna langsung dan pengguna tidak langsung. Pengguna langsung adalah masyarakat setempat (aparatur desa, nelayan, petani, Badan Pengelola Daerah Perlindungan Mangrove (BPDPM) serta Pengusaha Keramba Jaring Apung (PKJA)). Pengguna tidak langsung adalah dinas teknis yaitu Badan Perencanaan Pembangunan Daerah (Bappeda), Badan Pertanahan (BPN), Dinas Kelautan dan Perikanan (DKP), Dinas Perkebunan dan Kehutanan (Disbunhut), Badan Lingkungan Hidup (BLH), serta Lembaga Swadaya Masyarakat Mitra Bentala.

2. Pemetaan para aktor di Desa Pulau Pahawang terbagi menjadi 3 kuadran, yaitu: keyplayers, crowd dan subject. Kuadran keyplayers terdapat Dinas perkebunan dan Kehutanan (Disbunhut), Lembaga Swadaya Masyarakat (LSM) Mitra Bentala, Badan Pengelola Daerah Perlindungan Mangrove (BPDPM). Kuadran crowd terdapat Badan Perencanaan Pembangunan Daerah (Bappeda), Badan Pertanahan (BPN), Dinas Kelautan dan Perikanan (DKP), Dewan Perwakilan Rakyat Daerah (DPRD), dan masyarakat Desa pulau Pahawang. Kuadran subject terdapat Badan Lingkungan Hidup (BLH).

\section{DAFTAR PUSTAKA}

Arikunto, S. 2011. Prosedur Penelitian Suatu Pendekatan Praktek. Buku. Rineka Cipta. Jakarta. 413p.

Direktorat Jenderal Pengembangan Destinasi Pariwisata. 2009. Prinsip dan Kriteria Ekowisata Berbasis Masyarakat. Buku. Direktorat Produk Pariwisata, Direktorat Jenderal Pengembangan Destinasi Pariwisata dan Departemen Kebudayaan dan Pariwisata dan WWF-Indonesia. Jakarta. 9p. 
Firdaus, I., A. 2012. Konservasi Hutan Mangrove sebagai Pendidikan di Estuari Jembranai, Bali. Diakses pada 28 September 2015 pukul 20.05 WIB. http://mikroteknologi.blogspot.co.id/2012/05/konservasi-hutan-mangrove-sebagai.html.

ICWRMIP. 2013. Pengenalan dan simulasi score-card dalam rangka monitoring dan evaluasi penanganan WS Citarum. Sub-component 8.2 : Independent Monitoring \& Evaluation (IME). 46p.

Krott, M. 2005. Forest Policy Analysis. Book. Springer. Netherland. 334p.

Kustanti, A. 2011. Manajemen Hutan Mangrove. Buku. IPB Press. Bogor. 248p.

. 2013. Evolusi Hak Kepemilikan dan Penataan Peran Para Pihak pada Pengelolaan Ekosistem Hutan Mangrove dengan Kemunculan Tanah Timbul. Disertasi. Program Pascasarjana Ilmu Pengelolaan Hutan. Institut Pertanian Bogor. Bogor. 171p.

Kustanti, A., B. Nugroho., D. Durusman., C. Kusmana., D. Nurrochmat., M. Krott., and C. Schusser. 2014. Actor, interest and conflict in sustainable mangrove forest management - a case from Indonesia. International Journal of Marine Science 2014. 4 (16): 150 159.

Notoatmodjo, S. 2002. Metodologi Penelitian Kesehatan. Buku. Rineka Cipta. Jakarta. 208p.

Nurfatriani, F., Darusman, D., Nurrochmat, D.R., dan Yustika. A.E. 2015. Analisis pemangku kepentingan dalam transformasi kebijakan fiskal hijau di Bogor. Jurnal Analisis Kebijakan Kehutanan. 12 (2): 105 - 124.

Priyono, A., Yuliani L.S., Ilminingtyas T., dan Hakim T.L. 2010. Beragam Produk Olahan Berbahan Dasar Mangrove. Buku. KeSEMat. Semarang. 61p.

Purnobasuki, H. 2004. Potensi tanaman mangrove sebagai tanaman obat Universitas Airlangga. Biota, jurnal ilmiah ilmu-ilmu hayati. IX (2): 125 - 126.

Purwanto, A. D. 2014. Analisis sebaran dan kerapatan mangrove menggunakan citra landsaT 8 DI Segara Anakan. Cilacap. Jurnal Seminar Nasional Penginderaan Jauh 2014. Pengolahan Data dan Pengenalan Pola: 232 - 241.

Rahmawaty. 2006. Upaya Pelestarian Mangrove berdasarkan Pendekatan Masyarakat. Karya Ilmiah. Universitas Sumatera Utara. Medan. 19p.

Reed MS et al. 2009. Who's in and why? a typology of stakeholder analysis methods for natural resource management. Journal of Environmental Management. 90 (2009): 1933 $-1949$.

Sriyana, 2005. Pendekatan model pengendalian untuk mengurangi risiko akibat gelombang tsunami di Semarang. Jurnal Mahasiswa Program Doktor Teknik Sipil Universitas Diponegoro. 13 (2): $106-113$.

Suryawan, A., dan Mayasari, A. 2012. Potensi ragam pemanfaatan hasil hutan bakau bukan kayu ekosistem mangrove di Desa Air Banua Manado. Seminar dan Pameran HasilHasil Penelitian Tahun 2012. 72-85. 
Tarigan, M.S. 2008. Sebaran dan luas hutan mangrove di wilayah pesisir teluk pising utara Pulau Kabaena Provinsi Sulawesi Tenggara. Jurnal Sains. 12 (2): 108 - 112.

Wakka, A.K. 2014. Analisis stakeholder pengelolaan kawasan hutan dengan tujuan khusus (KHDTK) Mengkendek, Kabupaten Tana Toraja, Provinsi Sulawesi Selatan. Jurnal Penelitian Kehutanan Wallacea. 3 (1): 47 - 55. 